\title{
Does Impaired Social Motivation Drive Imitation Deficits in Children with Autism Spectrum Disorder?
}

\author{
Hannah M. Van Etten ${ }^{1}$ • Leslie J. Carver ${ }^{1}$ \\ Received: 3 April 2015 / Accepted: 27 June 2015 /Published online: 8 July 2015 \\ (C) Springer Science+Business Media New York 2015
}

\begin{abstract}
There is clear evidence that children with autism spectrum disorder display deficits in imitation but little consensus on the reasons for these deficits. In this paper, we review evidence that suggests that the presence of imitation deficits may be explained in part by social communication deficits, specifically by impaired social motivation. First, we discuss the social role that imitation serves in typical development and how imitation may facilitate the forming of social connections. Then, we describe evidence that suggests that both the impairments in imitation that have been seen in some areas, and the relative sparing of imitation in other areas, can be explained by impairments in social motivation. Lastly, the importance of therapies to incorporate social communication skills when targeting imitation is emphasized. As more research needs to be done to empirically examine this hypothesis, suggestions of directions for future studies are discussed.
\end{abstract}

Keywords Autism spectrum disorder - Social motivation . Imitation

Engaging in imitation serves two functions during development: it provides children with information about their surroundings and enables them to connect with a social partner (Uzgiris 1981). Imitation limits the need to learn new skills solely through trail-and-error (Nielsen et al. 2008). Children use imitation to develop relationships and interact with other children and adults at a time when they lack the capacity to do so verbally (Eckerman et al. 1979, 1989; Meltzoff and Moore

Hannah M. Van Etten

hvanette@ucsd.edu

1 Department of Psychology, University of California, San Diego, 9500 Gilman Drive MC0109, La Jolla, CA 92093, USA
1992). Using imitation, children are able to establish a feeling of shared mutuality with a peer and indicate that they are similar to each other (Uzgiris 1981). It is largely thought that engaging in imitation is in part motivated by a desire to connect with a social partner.

Children with autism spectrum disorders (ASD) display deficits in social communication that may impact their ability or desire to imitate (Ingersoll 2008b; Roeyers et al. 1998; Whiten and Brown 1998). One aspect of social communication that may be important for imitation is social motivation. Children with ASD are though not to be motivated by social interactions in the same manner as typically developing children (see Stavropoulos and Carver 2013 for a review). For a skill like imitation-where one of the functions is to interact with social partners - the social interaction that occurs may not be sufficiently motivating for children with ASD to engage in imitative behaviors. Deficits in imitation can be seen in children with ASD when compared to typically developing and developmentally delayed children (see Edwards 2014 for a review). Interestingly, imitation deficits are not seen in all areas of imitation - intact imitation can be seen depending on the context and type of imitation (e.g., spontaneous versus elicited, Ingersoll 2008a).

Due to the social function that imitation typically serves and the social deficits that are a defining characteristic of ASD, research needs to focus on how deficits in social communication may impact imitation. Although some theorists have mentioned the possibility that social deficits-specifically social motivation-drive imitation deficits in ASD (Ingersoll 2008b; Roeyers et al. 1998; Whiten and Brown 1998), this is the first paper to do a thorough review of the topic. We suggest that decreased social motivation in children with ASD can explain many of the deficits in imitation. If so, this will have important implications for therapies that concentrate on improving imitation. 
The purpose of this paper is to understand the relation between social motivation and imitation deficits in ASD. By examining imitation from a primarily social viewpoint, we aim to demonstrate that deficits in social motivation in children with ASD play a fundamental role in imitation deficits. Part 1 will examine the role of social factors in motivating imitation. In part 2, we will outline where imitation deficits are seen in children with ASD and discuss how impaired social motivation may contribute to these deficits. Part 3 will discuss how this approach can be used in interventions that target imitation. In conclusion, emphasis will be placed on the importance of empirically examining the impact that social motivation has on imitation ability.

\section{Part 1: Imitation in Typical Development}

Imitation emerges early in typical development, with evidence indicating that at least some imitation ability is present even in neonates (Meltzoff and Moore 1977, 1989). Children use imitation to learn about the world around them (Uzgiris 1981). Although not restricted to a human model, imitation normally involves engaging in some form of interpersonal interaction with another human. Consequently, imitation also serves a social function, enabling individuals to establish a feeling of mutuality and shared understanding with others (Uzgiris 1981).

From an early age, infants respond positively to their caregivers' imitative behaviors through smiling and establishing eye contact (Meltzoff 1990; Nadel 2002). As they get older, infants engage in reciprocal imitation of their caregivers' vocalizations and facial expressions. They continue to use reciprocal imitation into toddlerhood, with imitation serving a significant social role in dyadic interactions. It is through the use of imitation that infants and toddlers are able to interact, build relationships, and form connections with others (Asendorpf and Baudonnière 1993; Eckerman et al. 1989; Eckerman and Stein 1982; Kuczynski et al. 1987; Nadel 2002; Nadel-Brulfert and Baudonniere 1982; Nielsen and Dissanayake 2004).

\section{Social Motivation and Imitation}

Engaging in social interactions with others is thought to be intrinsically motivating. People likely engage with others because they find doing so rewarding, rather than because they expect to benefit from these interactions. Social motivation has been demonstrated neurologically: putative reward circuits in the brain are activated by social stimuli- such as faces - in both children and adults (Kampe et al. 2001; Stavropoulos and Carver 2014a). From a behavioral perspective, the motivational value of social interactions can be seen at a young age. Toddlers choose to work in collaboration with a peer to gain a reward as opposed to gain the reward independently, even when the effort needed to gain the reward does not differ (Rekers et al. 2011). Adults enjoy mutual cooperation (Fehr and Camerer 2007) as well and will exert extra effort to obtain social rewards (Hayden et al. 2007). With evidence indicating the inherent reward value of social stimuli and interactions, it would be expected that engaging in imitation — which functions as a way to interact with other social partners - is socially motivated.

Imitation likely serves a social function, but few studies have directly examined the role of social motivation in imitation ability. To assess this relationship, Nielsen (2006) manipulated the social engagement of a model (i.e., aloof or socially engaged) during an imitation paradigm. He expected that toddlers would have greater motivation to imitate a socially engaging model than an aloof model and therefore would have higher rates of imitation when interacting with the socially engaging model. Twenty-four-month-old participants in both groups imitated the model, but participants in the aloof condition engaged in the end goal (i.e., opening a box) less frequently. The author suggests that toddlers in the aloof condition initially imitated in order to initiate interaction, but when this proved unsuccessful, they were no longer motivated to interact by imitating and achieving the end goal. However, the model's behavior was unnatural- they neither smiled nor made eye contact with the child. Rather than responding to the lack of social engagement, children may have been responding to the unnatural behavior of the model.

Overimitation may be an indicator of social motivation. The term overimitation is used to describe instances in which children imitate actions even when those actions are irrelevant to the task at hand (e.g., Horner and Whiten 2005; Nagell et al. 1993; Nielsen 2006). One reason that children are thought to engage in overimitation is out of a desire to connect socially with another person (Carpenter 2006; Nielsen 2006; Nielsen and Carpenter 2008; Over and Carpenter 2012; Tomasello et al. 2005). Watson-Jones et al. (2014) found that when primed with a video demonstrating ostracism as opposed to affiliation, children engaged in imitative behaviors that adhered more closely to the modeled behavior. Children also engaged in higher fidelity imitation for causally opaque actions (i.e., those actions which the purpose was unclear), such as opening a box with an unnecessary instrument. These findings suggest that children will engage in overimitation out of a desire to be part of a social group. The propensity to engage in overimitation supports the idea that social motivation is an important factor in imitation.

To further examine the social function of overimitation, Nielsen et al. (2008) manipulated the contingent interaction of the model by using a live, videotaped, and interactive (i.e., live video streaming) model during an imitation paradigm. If social motivation played a key role, overimitation should be higher in both live and interactive conditions than the videotaped condition, because in these conditions, the 
children engaged socially with the model. Twenty-fourmonth-old children were less likely to imitate the exact actions modeled in the video condition as compared to the both the live and interactive video conditions. Results of this study indicate that children are more likely to overimitate when social engagement occurs. Several other studies have shown that rates of imitation are higher when exposed to a live model than a video model (Barr and Hayne 1999; Barr et al. 2007a, b; Hayne et al. 2003; Zack et al. 2009; McCall et al. 1977). These studies suggest an important role of social engagement in motivating imitative behaviors.

Typically developing children use imitation to interact and connect with social partners. Engaging in imitation is likely motivated by social factors, such that children imitate others because they enjoy and are motivated by social interactions. When social components are removed from imitation, children change the manner in which they imitate. This leads to the question of what happens to imitation when children are not motivated by social factors.

\section{Part 2: Imitation in Autism Spectrum Disorders}

Children with ASD display deficits in imitation abilities compared to typically developing and other developmentally delayed groups (e.g., DeMyer et al. 1972; Rogers and Pennington 1991). The first systematic study examining imitation deficits in children with ASD compared the performance of children with ASD to typically developing and developmentally delayed children on body and action-on-object imitation (DeMyer et al. 1972). Children with ASD performed worse on these tasks. Imitation deficits have been shown across a variety of tasks, including impaired performance on spontaneously imitating others' facial expressions (Scambler et al. 2007), actions-on-object imitation tasks, and imitating motor movements (Rogers et al. 2003). Additionally, a lack of imitative abilities has been shown to differentiate children with ASD from those with other developmental disorders as early as 2 years of age (Charman et al. 1997) and is correlated with ASD severity scores (Rogers et al. 2003).

Edwards (2014) reviewed 53 studies that investigated imitation performance in ASD. A wide range of inclusionary criteria were employed, including incorporating studies in the meta-analysis only if imitation was directly assessed using behavioral measures. Results of the meta-analysis showed that individuals with ASD, on average, performed 0.81 standard deviations below individuals without ASD on imitation tasks. The average Autism Diagnostic Observation Schedule (ADOS) of participants with ASD was negatively associated with imitation performance, indicating that those with more severe ASD performed worse in comparison to their non-ASD counterparts. These findings are consistent with other such reviews that find individuals with ASD to be impaired in their imitation ability in comparison to control groups (Rogers 1999; Smith and Bryson 1994; Williams et al. 2004).

However, not all studies find individuals with ASD to be impaired in imitation. There are a handful of studies that find no such deficit (Charman and Baron-Cohen 1994; Morgan et al. 1989) or find deficits that differ based on the task type (e.g., Rogers et al. 2003; Whiten and Brown 1998). Seemingly contradictory findings among imitation tasks may be due in part to different operational definitions of imitation that researchers use (Sevlever and Gillis 2010). The ASD imitation literature tends to use the term imitation broadly to refer to many different aspects of imitation. This is problematic because imitation, when not defined further, can refer to four different aspects of imitation - stimulus enhancement, emulation, mimicry, and true imitation (see Sevlever and Gillis 2010 for a review). While differentiating between the various aspects of imitation can be difficult, as it is largely dependent on the motivation of the imitator, it is important to attempt to make a clear distinction in order to gain a complete picture of imitation deficits in ASD. It may be the case that studies that did not find a difference in imitation ability examined a different aspect of imitation than those that did find a difference.

Numerous theories have arisen as to why children with ASD display imitation deficits. Two of the more prominent explanations include deficits in general motor ability (Jones and Prior 1985; Rogers and Pennington 1991; Vanvuchelen et al. 2007) and the mirror neuron hypothesis (Perrett 2001). However, current theories fail to explain instances of intact imitation abilities. For example, the general motor deficit explanation posits that children with ASD do not have deficits in imitation per se, but rather difficulties in fine and gross motor functioning impede imitation. If general motor difficulties underlie imitation deficits, then deficits would be seen in all aspects of imitation that rely on motor ability, but several studies have found evidence to the contrary (Rogers et al. 1996; Rogers et al. 2003; Zachor et al. 2010). The mirror neuron hypothesis suggests that imitation deficits can be attributed by dysfunction in the brain systems that allow individuals to match their actions with others. If there were a pronounced dysfunction in the mirror neuron hypothesis - which a recent review by Hamilton (2013) calls into question - then we would also expect imitation to be impacted regardless of task requirements. Both of these theories fail to explain studies that show uneven imitation performance in ASD. In order to understand what underlies imitation deficits, theories need to be able to account for these seemingly contradictory findings.

\section{Social Motivation and Imitation}

Imitation has been studied extensively in ASD, but few studies have examined the link between social communication and imitation. Although children with ASD show a range of 
deficits, evidence suggests that decreased social communication skills - in particular, a lack of motivation to engage with others socially - may drive deficits in imitation (Roeyers et al. 1998; Whiten and Brown 1998; Ingersoll 2008b). By looking at situations in which imitation is differentially impacted, we can understand if deficits in social motivation affect performance on specific imitation tasks.

Recently, researchers have started viewing social impairments in ASD in relation to social motivation. The social motivation hypothesis (Chevallier et al. 2012; Dawson 2008; Dawson et al. 2002, 2005; Grelotti et al. 2002; Schultz 2005; Stavropoulos and Carver 2013) posits that what underlies many of the social deficits in ASD is a lack of motivation to engage in social activities. Children with ASD are thought to find social activities to be less intrinsically motivating than typically developing children. Stavropoulos and Carver (2014b) showed that children with ASD display smaller ERP responses (stimulus preceding negativity and feedbackrelated negativity) when anticipating and processing social rewards than typically developing children. This indicates that social stimuli have less reward value for children with ASD than for typically developing children. As a result, social motivation impairments may affect imitation as well.

To understand the role of motivation in imitation, Ingersoll et al. (2003) manipulated the feedback that children received upon imitation. Two sets of toys were used in this experiment. One set of toys provided sensory feedback while a second did not. Although no difference in overall imitation ability between the two groups was found, children with ASD performed significantly better in the condition where the toy gave sensory feedback. Imitation did not differ between the two toy types for typically developing children. To examine if this was due to a difference in preference for sensory toys by the children with ASD, they measured the percentage of 10 -s intervals in which the subject was engaged with the sensory toys versus the nonsensory toys. Results showed that both typically developing children and children with ASD engaged with the sensory more than the non-sensory toys, indicating that both groups preferred the sensory toys to the non-sensory toys.

Ingersoll et al. concluded that the difference in imitation between the two sets of toys might be due to a difference in motivation. Typically developing children were found to display more social behaviors (i.e., social initiations, coordinated joint attention, directing positive affect towards the experimenter) with the experimenter compared to the children with ASD, suggesting that typically developing children may have been motivated by the social interactions that occur during imitation. Therefore, they imitated the experimenter in both conditions. However, the children with ASD displayed fewer social behaviors and were thought not to be as motivated to imitate by social interaction. Instead, when motivated to imitate by the sensory feedback, they did imitate. This implies that children with ASD can imitate when motivated.

\section{Function of Imitation}

In children with ASD, imitation may serve a different function than in typically developing children. This may explain why, rather than an overall imitation deficit in ASD, different imitation tasks are more impaired than others. Children with ASD perform worse on tasks that measure spontaneous as opposed to elicited imitation (Whiten and Brown, 1999; McDuffie et al. 2007; Ingersoll 2008a). Ingersoll (2008a) examined this by comparing imitation ability in both a naturalistic, spontaneous setting and a structured, elicited setting. In the elicited condition, the participant was seated at a table and instructed to watch as the experimenter performed certain actions on toys. After each demonstration, the participant was told, "You do it." During the spontaneous condition, the participant was seated on the floor with the experimenter and a variety of toys (in duplicate) spread across the room. The participant and experimenter engaged in free play, with the experimenter contingently imitating the actions of the child for $2 \mathrm{~min}$. After the contingent imitation, the experimenter instructed the child to watch and modeled an action on a toy. The experimenter continued contingently imitating the child for $45 \mathrm{~s}$ before performing another model. Typically developing children performed equally in both spontaneous and elicited conditions and imitated more actions than the children with ASD. Children with ASD performed significantly worse on the spontaneous imitation tasks than on the elicited tasks.

Differences in ability between spontaneous and elicited conditions suggest a role of social motivation. During spontaneous imitation conditions, the individual determines if and when they will imitate. If they choose to imitate, this may serve as a social interaction with the experimenter. During elicited imitation, explicit instructions to imitate are given. In this instance, the individual may imitate to comply with the experimenter's instructions or because it is clear that imitation is what is expected of them. The lack of imitation in the spontaneous conditions may show a lack of social motivation to engage with others, rather than a lack of imitative ability (Whiten and Brown, 1999; Ingersoll 2008a, b). This implies that children with ASD are more impaired in situations when the imitation serves a social function (McDuffie et al. 2007).

Even when children with ASD do imitate, they are not as sensitive to the social cues present in the imitative environment as typically developing children. Hobson and Lee (1999) examined if children were able to imitate the style in which the experimenter performed an action. The experimenter modeled an action in either a harsh or a gentle manner, with the participants later given the opportunity to imitate the experimenter. Although children with ASD were able to imitate the actions the experimenter performed as well as a group of developmentally delayed children, children with ASD did not imitate the style (i.e., harsh versus gentle) in which the experimenter performed the actions as well as the developmentally delayed 
children. Imitating the style as well as the action indicates a desire to be similar to the experimenter, to show that "I am like you." Therefore, the authors suggest that a lack of imitating the style may be due to a lack of motivation in children with ASD to engage and identify with others through imitation.

Additionally, this gives important insight into the function of imitation in children with ASD. When imitation serves an instrumental purpose, the style in which the action is performed is less important as long as the end goal is achieved using the most relevant actions. If the imitation serves a social purpose, then the style in which the action is performed is just as important as the action itself. By imitating the style in addition to the action, the developmentally delayed children may have been using imitation to form a social bond with the experimenter. In contrast, the children with ASD imitated for instrumental reasons, so the style was less relevant.

Several studies have shown imitation of non-meaningful actions to be more impaired than meaningful actions (Rogers et al. 1996; Stone et al. 1997; Zachor et al. 2010). Whether this difference is specific to children with ASD is still to be determined. However, children with ASD are particularly impaired in imitating body movements and gestures, arguably nonmeaningful, in comparison to imitating actions-on-objects (e.g., DeMyer et al. 1972; Stone et al. 1997; Zachor et al. 2010). Imitation serves an instrumental purpose when it is meaningful (e.g., children are learning something to do with the objects they are given). On the other hand, engaging in nonmeaningful imitation neither teaches a new skill nor models how to complete a desired result. This could explain why children with ASD, who show impairments in social motivation, are impacted in the imitation of non-meaningful actions.

\section{Overimitation}

Engaging in overimitation, as mentioned previously, serves as a way to socially engage with another person and is thought to be motivated be this desire. Due to deficits in social motivation, it would be expected that children with ASD display lower levels of overimitation than other children. Nielsen and Hudry (2009) examined overimitation in children with ASD in comparison to children with Down syndrome. To measure this, children were shown a set of actions with an object that was used to open a wooden box in order to gain a toy inside. The actions that were modeled were not the only way to open the box; the children could ignore the object and instead open the box with their hands. If the children used the object to open the box as opposed to their hands, this was taken as evidence of the children engaging in overimitation. However, results of the study did not support their hypothesis: children with ASD engaged in overimitation at the same rate as children with Down syndrome, with neither group showing deficits in this ability. In a subsequent study comparing overimitation in children with
ASD to typically developing children, Nielsen et al. (2013) found similar results: children with ASD engaged in overimitation to the same extent as typically developing children. As the authors mention, their results need to be interpreted with some caution as their group involved higher functioning children with ASD, which may not be indicative of overimitation ability in the larger ASD community.

While both Nielsen and Hudry (2009) and Nielsen et al. (2013) suggest that their findings argue against the influence of social motivation on imitation in ASD, it is possible that results were confounded by the fact that they were unable to separate out the social component of imitation from the learning component. To improve upon their work and others, Marsh et al. (2013) examined overimitation with the use of familiar actions and objects, thereby removing the learning component that may be a large part of imitating novel actions on objects. Additionally, Marsh et al. compared children with ASD to two typically developing groups: one matched on verbal mental age and the other matched on chronological age. Participants watched as a demonstrator modeled both necessary (e.g., unclipping and removing the lid) and unnecessary (e.g., tapping the box twice) familiar actions to open a box and remove a toy inside. Participants were also instructed to get the toy "as fast as you can" to emphasize the goal of the action and to insure that engaging in overimitation was counterproductive to the goal. Typically developing children engaged in overimitation significantly more than children with ASD, even though they understood that the unnecessary actions were "silly" when questioned later. This suggests that typically developing children engaged in overimitation to connect with the demonstrator, while children with ASD did not choose to overimitate. Because of the mixed results on overimitation in ASD, and the importance of determining if deficits in social motivation impact imitation, future studies need to be designed that examine a wide variety of children with ASD and take into consideration the impact that task familiarity may have on overimitation.

\section{Using Imitation to Increase Social Interactions}

In addition to the social connection that occurs in imitation, studies have investigated the effect that being imitated has on children with ASD. Improvements in social behaviors and imitation abilities have been shown when adults imitate children with ASD (Tiegerman and Primavera 1984; Dawson and Adams 1984; Nadel et al. 2000; Heimann et al. 2006). Nadel et al. (2000) examined whether using a still-face paradigm and contingent imitation in children with ASD would increase their social initiations. They designed a study that combined the still-face paradigm (Tronick et al. 1978), normally used in typically developing children, with imitation. First, non-verbal and lower functioning children with ASD were exposed to a 
modified still-face paradigm. During this portion, the experimenter sat with a still face, still body, and no vocalization while the child was free to roam the room. After $3 \mathrm{~min}$, the experimenter approached the child and for 3 min imitated everything the child was doing. This included their facial expressions, body gestures, vocalizations, and the actions they were engaged in with toys. After the imitation portion, the experimenter engaged in the still-face paradigm again for 3 min. Facial expressions, eye gaze, proximity, social gestures, and vocalizations of the participants were then coded for each of the intervals.

Although children with ASD did not show any concern in the first still-face interval, during the second, they showed significant changes in their social behavior. They spent more time looking at, touching, and being in close proximity to the experimenter during the second still-face episode. During the imitation session, participants spent less time looking away and more time looking at, as well as touching, the experimenter in comparison to the first still-face interval. They also spent more time engaged in positive social gestures (i.e., offer, show, imitate, and request). In follow-up studies using similar paradigms, researchers showed that the increase in positive social behaviors is in response to the child being imitated, as opposed to in response to a general contingent interaction (Escalona et al. 2002; Field et al. 2001; Heimann et al. 2006).

Heimann et al. (2006) also examined if an increase in imitation would be seen beyond the experimental setting. Participants who were imitated improved their imitation scores on the Psychoeducational Profile-Revised (PEP-R, Schopler et al. 1990) in comparison to children who had only been exposed to non-imitative contingent interactions. These studies indicate that what underlies deficiencies in imitation in ASD may be connected to a poor ability to understand social relationships. Imitating children with ASD may in turn facilitate their social expectancies of the world around them and lead to improvements in many different social behaviors, including imitation (Escalona et al. 2002; Field et al. 2001; Heimann et al. 2006; Nadel et al. 2000).

\section{Part 3: Implications for Therapy and Future Studies}

It is important that therapies designed to improve imitation ability take social motivation into consideration. The move away from strictly behavioral therapies and towards therapies that include a focus on social development may be crucial for improving imitation abilities in children with ASD. If, as we propose, difficulties in social motivation impact imitation deficits, then improving imitation cannot be done without focusing on the social aspect of imitation as well.

In the past, interventions designed to target imitation were largely taught from a behavioral perspective, with the focus on discrete trial training (e.g., Leaf and McEachin 1999; Maurice et al. 1996). During sessions that employed this technique, targeted imitation behaviors were separated into different sub-skills that were taught individually in blocks of ten trials. These behaviors were taught with the use of contingent reinforcements (i.e., access to a preferred item upon correct response) and through the use of a variety of different prompts (e.g., hand-over-hand) to elicit correct responses. These discrete trial techniques are an effective way to teach a variety of imitative behaviors (e.g., Baer et al. 1967; Lovaas et al. 1966; Metz 1965). However, early studies did not examine the generalizability of these abilities to non-treatment environments. Research on discrete trial training suggests a structured environment, artificial reinforcements, and specific verbal directives that are commonly used in these settings impede spontaneous appearance of skills and affects their ability to generalize to other environments (Carr 1981; Koegel et al. 1987; Lovaas 1977; Spradlin and Siegel 1982). Additionally, when skills are taught in isolation, learning is not representative of the typical adult-child or child-child interactive setting in which imitation naturally occurs (Schreibman et al. 1991). Ensuring that imitation is taught in such a way as to promote generalization and spontaneity is particularly important because of the social function of imitation.

In response to many of the limitations related to discrete trial training, a variety of naturalistic behavioral treatments have arisen (e.g., pivotal response training). Naturalistic behavioral treatments draw on the strengths of behavioral techniques that promote learning while incorporating techniques that promote social communicative behaviors in typically developing children (Ingersoll and Schreibman 2006). For example, these treatments use behavioral techniques like prompting and multiple trials while at the same time using social communicative techniques such as following the child's lead and engaging in contingent imitation. Naturalistic behavioral treatments are effective at improving generalization across different settings (Charlop-Christy and Carpenter 2000; Spradlin and Siegel 1982). These treatments, with the focus on promoting a variety of skills in a naturalistic environment, may be the key to improving imitation.

One such naturalistic behavioral approach focuses on improving imitation by approaching it from a social prospective. Reciprocal imitation training (RIT) (Ingersoll and Schreibman 2006) is a naturalistic behavioral intervention designed to focus on improving imitation in children with ASD while they engage in social interactions with an adult (Ingersoll 2008b). This form of therapy, and others like it that include a social component, is particularly beneficial as imitation is related to other social skills. RIT focuses on three main goals: improving intrinsic motivation, increasing spontaneity, and improving generalizability. It attempts to teach children with ASD that imitation can be used not only to learn new things but also as a way to interact with another person (Ingersoll 2008b). This intervention has been shown as an effective way to improve 
object (Ingersoll and Schreibman 2006) and meaningful gesture (Ingersoll and Gergans 2007) imitation. It has also been used as an effective parent-led intervention to improve object imitation (Ingersoll and Gergans 2007). In addition to the direct improvements that are seen on a variety of imitation skills, improvements have also been seen in other social communication behaviors (Ingersoll et al. 2013) that were not targeted during the intervention, such as coordinated joint attention and pretend play (Ingersoll and Schreibman 2006). This speaks to the importance of improving imitation, as it influences other aspects of social ability.

Studies are still needed that directly and empirically investigate if social communication deficits, specifically deficits in social motivation, play a foundational role in imitation deficits. Many of the studies discussed in this paper did not empirically test this hypothesis. Instead, authors made post hoc conclusions about the role of social motivation in imitation. To gain a more complete understanding of imitation deficits in ASD, it is vital for future studies to investigate this connection explicitly. Studies might be designed that manipulate either the social availability of a model or the model's emotional expression to examine whether imitation ability is influenced by the social characteristics of the model (Nielsen 2006; Nielsen and Carpenter 2008). Future studies can also manipulate the degree to which children with ASD feel connected to a model, as increasing the feeling of mutuality with a person may increase the motivation to imitate. The social characteristics of the model would be expected to influence typically developing children's tendency to imitate more than children with ASD. Additionally, removing the social aspects of imitation might increase children with ASD's desire to imitate. These findings would provide evidence that the social aspects need to be considered when designing interventions, with possible implications for a wide range of therapies that involve interpersonal interactions. It is important for researchers to not only focus on designing imitation studies in a structured, laboratory setting but to examine imitation in naturalistic settings that better reflect the day-to-day environment in which imitation occurs. By doing so, we can gain a more complete understanding of imitation ability in children with ASD.

\section{Conclusion}

The social function that imitation serves in typical development has been well established over the past 30 years. However, little research has been devoted to examining how social motivation impacts imitation ability. The purpose of this paper was to review evidence that impaired social motivation plays an integral role in imitation deficits that are seen in children with ASD. The first section of the paper served to establish the social role of imitation in typically developing children. Additional evidence was presented to demonstrate that typically developing children are motivated by social interactions and that this motivation influences imitation. The second section discussed instances in which imitation is and is not impacted in children with ASD and reviewed evidence that seemingly contradictory findings about imitation ability can be explained by impairments in social motivation that are present in children with ASD. The third section discussed how imitation is targeted in therapies and emphasized the importance for therapies to continue incorporating social communication skills while focusing on improving imitation. As more research needs to be done to further empirically test this hypothesis, we provided suggestions for such studies.

One difficulty in reviewing the literature on imitation in ASD comes from the varying definitions of imitation researchers use. Inconsistencies in definition likely have contributed to the varying outcomes in imitation studies. Future papers should use a more exact definition of imitation, such as was done in a recent review by Edwards (2014). Additionally, we left open the direction of the relationship between social communication deficits and imitation. Do social communication deficits, specifically those that are seen in individuals with ASD, negatively impact the ability to imitate others, leading to imitation deficits? Or, do imitation deficits precede social communication deficits, such that deficits in imitation hinder the development of social communication skills? While the question of causality may be difficult to empirically examine, it is important that researchers continue to attempt to gain headway in this area. Lastly, as many of the articles referenced are speculative in nature, it is vital that future studies directly test this hypothesis and a thorough review be completed once this occurs.

\section{References}

Asendorpf, J. B., \& Baudonnière, P.-M. (1993). Self-awareness and other-awareness: mirror self-recognition and synchronic imitation among unfamiliar peers. Developmental Psychology, 29(1), 88-95. doi:10.1037/0012-1649.29.1.88.

Baer, D. M., Peterson, R. F., \& Sherman, J. A. (1967). The development of imitation by reinforcing behavioral similarity to a model. Journal of the Experimental Analysis of Behavior, 10(5), 405-416. doi:10. 1901/jeab.1967.10-405.

Barr, R., \& Hayne, H. (1999). Developmental changes in imitation from television during infancy. Child Development, 70(5), 1067-1081. doi:10.1111/1467-8624.00079.

Barr, R., Muentener, P., \& Garcia, A. (2007a). Age-related changes in deferred imitation from television by 6 - to 18 -month-olds. Developmental Science, 10(6), 910-921. doi:10.1111/j.1467-7687. 2007.00641.x.

Barr, R., Muentener, P., Garcia, A., Fujimoto, M., \& Chávez, V. (2007b). The effect of repetition on imitation from television during infancy. Developmental Psychobiology, 49(2), 196-207. doi:10.1002/dev. 20208. 
Carpenter, M. (2006). Instrumental, social, and shared goals and intentions in imitation. In S. J. Rogers \& J. H. G. Williams (Eds.), Imitation and the social mind: autism and typical development (pp. 48-70). New York: Guilford Press.

Carr, E. G. (1981). Sign language. In O. I. Lovaas, A. Ackerman, D. Alexander, P. Firestone, M. Perkins, \& A. L. Egel (Eds.), The me book: teaching manual for parents and teachers of developmentally disabled children (pp. 153-161). Baltimore: University Park Press.

Charlop-Christy, M. H., \& Carpenter, M. H. (2000). Modified incidental teaching sessions a procedure for parents to increase spontaneous speech in their children with autism. Journal of Positive Behavior Interventions, 2(2), 98-112. doi:10.1177/109830070000200203.

Charman, T., \& Baron-Cohen, S. (1994). Another look at imitation in autism. Development and Psychopathology, 6(03), 403-413. doi: 10.1017/S0954579400006015.

Charman, T., Swettenham, J., Baron-Cohen, S., Cox, A., Baird, G., \& Drew, A. (1997). Infants with autism: an investigation of empathy, pretend play, joint attention, and imitation. Developmental Psychology, 33(5), 781-789. doi:10.1037/0012-1649.33.5.781.

Chevallier, C., Kohls, G., Troiani, V., Brodkin, E. S., \& Schultz, R. T. (2012). The social motivation theory of autism. Trends in Cognitive Sciences, 16(4), 231-239. doi:10.1016/j.tics.2012.02.007.

Dawson, G. (2008). Early behavioral intervention, brain plasticity, and the prevention of autism spectrum disorder. Development and Psychopathology, 20(03), 775-803. doi:10.1017/ S0954579408000370.

Dawson, G., \& Adams, A. (1984). Imitation and social responsiveness in autistic children. Journal of Abnormal Child Psychology, 12(2), 209-226. doi:10.1007/BF00910664.

Dawson, G., Carver, L., Meltzoff, A. N., Panagiotides, H., McPartland, J., $\&$ Webb, S. J. (2002). Neural correlates of face and object recognition in young children with autism spectrum disorder, developmental delay, and typical development. Child Development, 73(3), 700717. doi:10.1111/1467-8624.00433.

Dawson, G., Webb, S. J., Wijsman, E., Schellenberg, G., Estes, A., Munson, J., \& Faja, S. (2005). Neurocognitive and electrophysiological evidence of altered face processing in parents of children with autism: implications for a model of abnormal development of social brain circuitry in autism. Development and Psychopathology, null(03), 679-697. doi:10.1017/S0954579405050327.

de Hamilton, A. F. C. (2013). Reflecting on the mirror neuron system in autism: a systematic review of current theories. Developmental Cognitive Neuroscience, 3, 91-105. doi:10.1016/j.den.2012.09.008.

DeMyer, D. M. K., Alpern, G. D., Barton, S., DeMyer, W. E., Churchill, D. W., Hingtgen, J. N., \& Kimberlin, C. (1972). Imitation in autistic, early schizophrenic, and non-psychotic subnormal children. Journal of Autism and Childhood Schizophrenia, 2(3), 264-287. doi:10. 1007/BF01537618.

Eckerman, C. O., \& Stein, M. R. (1982). The toddler's emerging interactive skills. In Peer relationships and social skills in childhood (pp. 41-71). Springer New York.

Eckerman, C. O., Whately, J. L., \& McGehee, L. J. (1979). Approaching and contacting the object another manipulates: a social skill of the 1year-old. Developmental Psychology, 15(6), 585-593. doi:10.1037/ 0012-1649.15.6.585.

Eckerman, C. O., Davis, C. C., \& Didow, S. M. (1989). Toddlers' emerging ways of achieving social coordinations with a peer. Child Development, 60(2), 440-453. doi:10.2307/1130988.

Edwards, L. A. (2014). A meta-analysis of imitation abilities in individuals with autism spectrum disorders. Autism Research, 7(3), 363380. doi:10.1002/aur.1379.

Escalona, A., Field, T., Nadel, J., \& Lundy, B. (2002). Brief report: imitation effects on children with autism. Journal of Autism and Developmental Disorders, 32(2), 141-144. doi:10.1023/ A:1014896707002.
Fehr, E., \& Camerer, C. F. (2007). Social neuroeconomics: the neural circuitry of social preferences. Trends in Cognitive Sciences, 11(10), 419-427. doi:10.1016/j.tics.2007.09.002.

Field, T., Field, T., Sanders, C., \& Nadel, J. (2001). Children with autism display more social behaviors after repeated imitation sessions. Autism, 5(3), 317-323. doi:10.1177/1362361301005003008.

Grelotti, D. J., Gauthier, I., \& Schultz, R. T. (2002). Social interest and the development of cortical face specialization: what autism teaches us about face processing. Developmental Psychobiology, 40(3), 213225. doi:10.1002/dev. 10028.

Hayden, B. Y., Parikh, P. C., Deaner, R. O., \& Platt, M. L. (2007). Economic principles motivating social attention in humans. Proceedings of the Royal Society B: Biological Sciences, 274(1619), 1751-1756. doi:10.1098/rspb.2007.0368.

Hayne, H., Herbert, J., \& Simcock, G. (2003). Imitation from television by 24- and 30-month-olds. Developmental Science, 6(3), 254-261. doi:10.1111/1467-7687.00281.

Heimann, M., Laberg, K. E., \& Nordøen, B. (2006). Imitative interaction increases social interest and elicited imitation in non-verbal children with autism. Infant and Child Development, 15(3), 297-309. doi:10. 1002/icd.463.

Hobson, R. P., \& Lee, A. (1999). Imitation and identification in autism. The Journal of Child Psychology and Psychiatry and Allied Disciplines, 40(04), 649-659.

Horner, V., \& Whiten, A. (2005). Causal knowledge and imitation/ emulation switching in chimpanzees (Pan troglodytes) and children (Homo sapiens). Animal Cognition, 8(3), 164-181. doi:10.1007/ s10071-004-0239-6.

Ingersoll, B. (2008a). The effect of context on imitation skills in children with autism. Research in Autism Spectrum Disorders, 2(2), 332 340. doi:10.1016/j.rasd.2007.08.003.

Ingersoll, B. (2008b). The social role of imitation in autism: implications for the treatment of imitation deficits. Infants \& Young Children, 21(2), 107-119. doi:10.1097/01.IYC.0000314482.24087.14.

Ingersoll, B., \& Gergans, S. (2007). The effect of a parent-implemented imitation intervention on spontaneous imitation skills in young children with autism. Research in Developmental Disabilities, 28(2), 163-175. doi:10.1016/j.ridd.2006.02.004.

Ingersoll, B., \& Schreibman, L. (2006). Teaching reciprocal imitation skills to young children with autism using a naturalistic behavioral approach: effects on language, pretend play, and joint attention. Journal of Autism and Developmental Disorders, 36(4), 487-505. doi:10.1007/s10803-006-0089-y.

Ingersoll, B., Schreibman, L., \& Tran, Q. H. (2003). Effect of sensory feedback on immediate object imitation in children with autism. Journal of Autism and Developmental Disorders, 33(6), 673-683. doi:10.1023/B:JADD.0000006003.26667.f8.

Ingersoll, B., Walton, K., Carlsen, D., \& Hamlin, T. (2013). Social intervention for adolescents with autism and significant intellectual disability: initial efficacy of reciprocal imitation training. American Journal on Intellectual and Developmental Disabilities, 118(4), 247-261. doi:10.1352/1944-7558-188.4.247.

Jones, V., \& Prior, D. M. (1985). Motor imitation abilities and neurological signs in autistic children. Journal of Autism and Developmental Disorders, 15(1), 37-46. doi:10.1007/BF01837897.

Kampe, K. K. W., Frith, C. D., Dolan, R. J., \& Frith, U. (2001). Psychology: reward value of attractiveness and gaze. Nature, 413(6856), 589-589. doi:10.1038/35098149.

Koegel, R. L., O’Dell, M. C., \& Koegel, L. K. (1987). A natural language teaching paradigm for nonverbal autistic children. Journal of Autism and Developmental Disorders, 17(2), 187-200. doi:10.1007/ BF01495055.

Kuczynski, L., Zahn-Waxler, C., \& Radke-Yarrow, M. (1987). Development and content of imitation in the second and third years of life: a socialization perspective. Developmental Psychology, 23(2), 276-282. doi:10.1037/0012-1649.23.2.276. 
Leaf, R., \& McEachin, J. (1999). A work in progress: behavior management strategies and a curriculum for intensive behavioral treatment of autism. Drl Books.

Lovaas, O. I. (1977). The autistic child: Language development through behavior modification. New York: Irvington.

Lovaas, O. I., Berberich, J. P., Perloff, B. F., \& Schaeffer, B. (1966). Acquisition of imitative speech by schizophrenic children. Science, 151(3711), 705-707. doi:10.1126/science.151.3711.705.

Marsh, L., Pearson, A., Ropar, D., \& Hamilton, A. (2013). Children with autism do not overimitate. Current Biology, 23(7), R266-R268. doi: 10.1016/j.cub.2013.02.036.

Maurice, C. E., Green, G. E., \& Luce, S. C. (1996). Behavioral intervention for young children with autism: a manual for parents and professionals (1996) (vol. xiv). Austin: PRO-ED.

McCall, R. B., Parke, R. D., Kavanaugh, R. D., Engstrom, R., Russell, J., \& Wycoff, E. (1977). Imitation of live and televised models by children one to three years of age. Monographs of the society for research in Child Development, 1-94.

McDuffie, A., Turner, L., Stone, W., Yoder, P., Wolery, M., \& Ulman, T. (2007). Developmental correlates of different types of motor imitation in young children with autism spectrum disorders. Journal of Autism and Developmental Disorders, 37(3), 401-412. doi:10. 1007/s10803-006-0175-1.

Meltzoff, A. N. (1990). Foundations for developing a concept of self: The role of imitation in relating self to other and the value of social mirroring, social modeling, and self practice in infancy.

Meltzoff, A. N., \& Moore, M. K. (1989). Imitation in newborn infants: exploring the range of gestures imitated and the underlying mechanisms. Developmental Psychology, 25(6), 954-962. doi:10.1037/ 0012-1649.25.6.954.

Meltzoff, A. N., \& Moore, M. K. (1992). Early imitation within a functional framework: the importance of person identity, movement, and development. Infant Behavior and Development, 15(4), 479-505. doi:10.1016/0163-6383(92)80015-M.

Meltzoff, A. N., \& Moore, M. K. (1977). Imitation of facial and manual gestures by human neonates. Science, 198(4312), 75-78.

Metz, J. R. (1965). Conditioning generalized imitation in autistic children. Journal of Experimental Child Psychology, 4, 389-399.

Morgan, S., Cutler, P., Coplin, J., \& Rodrique, J. (1989). Do autistic children differ from retarded and normal children in Piagetian sensorimotor functioning? Journal of Child Psychology and Psychiatry, $30,857-864$.

Nadel, J. (2002). Imitation and imitation recognition: functional use in preverbal infants and nonverbal children with autism. The imitative mind: Development, evolution, and brain bases, 42-62.

Nadel, J., Croué, S., Mattlinger, M. J., Canet, P., Hudelot, C., Lécuyer, C., \& Martini, M. (2000). Do children with autism have expectancies about the social behaviour of unfamiliar people? A pilot study using the still face paradigm. Autism, 4(2), 133-145. doi:10.1177/ 1362361300004002003.

Nadel-Brulfert, J., \& Baudonniere, P. M. (1982). The social function of reciprocal imitation in 2-year-old peers. International Journal of Behavioral Development, 5(1), 95-109. doi:10.1177/ 016502548200500105 .

Nagell, K., Olguin, R. S., \& Tomasello, M. (1993). Processes of social learning in the tool use of chimpanzees (Pan troglodytes) and human children (Homo sapiens). Journal of Comparative Psychology, 107(2), 174-186. doi:10.1037/0735-7036.107.2.174.

Nielsen, M. (2006). Copying actions and copying outcomes: social learning through the second year. Developmental Psychology, 42(3), 555-565. doi:10.1037/0012-1649.42.3.555.

Nielsen, M., \& Carpenter, M. (2008). Reflecting on imitation in autism: introduction to the special issue. Journal of Experimental Child Psychology, 101, 165-169.

Nielsen, M., \& Dissanayake, C. (2004). Pretend play, mirror selfrecognition and imitation: a longitudinal investigation through the second year. Infant Behavior and Development, 27(3), 342-365. doi:10.1016/j.infbeh.2003.12.006.

Nielsen, M., \& Hudry, K. (2009). Over-imitation in children with autism and Down syndrome. Australian Journal of Psychology, 62(2), 6774. doi: $10.1080 / 00049530902758613$.

Nielsen, M., Simcock, G., \& Jenkins, L. (2008). The effect of social engagement on 24-month-olds' imitation from live and televised models. Developmental Science, 11(5), 722-731. doi:10.1111/j. 1467-7687.2008.00722.x.

Nielsen, M., Slaughter, V., \& Dissanayake, C. (2013). Object-directed imitation in children with high-functioning autism: testing the social motivation hypothesis. Autism Research, 6(1), 23-32. doi:10.1002/ aur. 1261.

Over, H., \& Carpenter, M. (2012). Putting the social into social learning: explaining both selectivity and fidelity in children's copying behavior. Journal of Comparative Psychology, 126(2), 182-192. doi:10. 1037/a0024555.

Perrett, D. I. (2001). Imitation, mirror neurons and autism. Neuroscience \& Biobehavioral Reviews, 25(4), 287-295. doi:10.1016/S01497634(01)00014-8.

Rekers, Y., Haun, D. B. M., \& Tomasello, M. (2011). Children, but not chimpanzees, prefer to collaborate. Current Biology, 21(20), 17561758. doi:10.1016/j.cub.2011.08.066.

Roeyers, H., Van Oost, P., \& Bothuyne, S. (1998). Immediate imitation and joint attention in young children with autism. Development and Psychopathology, 10(03), 441-450.

Rogers, S. J. (1999). An examination of the imitation deficit in autism. In J. Nadel \& G. Butterworth (Eds.), Imitation in infancy (pp. 254 283). New York: Cambridge University Press.

Rogers, S. J., \& Pennington, B. F. (1991). A theoretical approach to the deficits in infantile autism. Development and Psychopathology, 3(02), 137-162. doi:10.1017/S0954579400000043.

Rogers, S. J., Bennetto, L., McEvoy, R., \& Pennington, B. F. (1996). Imitation and pantomime in high-functioning adolescents with autism spectrum disorders. Child Development, 67(5), 2060-2073. doi:10.1111/j.1467-8624.1996.tb01843.x.

Rogers, S. J., Hepburn, S. L., Stackhouse, T., \& Wehner, E. (2003). Imitation performance in toddlers with autism and those with other developmental disorders. Journal of Child Psychology and Psychiatry, 44(5), 763-781. doi:10.1111/1469-7610.00162.

Scambler, D. J., Hepburn, S., Rutherford, M. D., Wehner, E. A., \& Rogers, S. J. (2007). Emotional responsivity in children with autism, children with other developmental disabilities, and children with typical development. Journal of Autism and Developmental Disorders, 37(3), 553-563. doi:10.1007/s10803006-0186-y.

Schopler, E., Reichler, R. J., Bashford, A., Lansing, M. D., \& Marcus, L. M. (1990). Individualized assessment of autistic and developmentally disabled children: Psychoeducational Profile Revised (PEP-R). Austin: Pro-Ed.

Schreibman, L., Kaneko, W. M., \& Koegel, R. L. (1991). Positive affect of parents of autistic children: a comparison across two teaching techniques. Behavior Therapy, 22(4), 479-490. doi:10.1016/ S0005-7894(05)80340-5.

Schultz, R. T. (2005). Developmental deficits in social perception in autism: the role of the amygdala and fusiform face area. International Journal of Developmental Neuroscience, 23(2-3), 125-141. doi:10.1016/j.ijdevneu.2004.12.012.

Sevlever, M., \& Gillis, J. M. (2010). An examination of the state of imitation research in children with autism: issues of definition and methodology. Research in Developmental Disabilities, 31(5), 976984. doi:10.1016/j.ridd.2010.04.014.

Smith, I. M., \& Bryson, S. E. (1994). Imitation and action in autism: a critical review. Psychological Bulletin, 116(2), 259-273. doi:10. 1037/0033-2909.116.2.259. 
Spradlin, J. E., \& Siegel, G. M. (1982). Language training in natural and clinical environments. Journal of Speech and Hearing Disorders, 47(1), 2. doi:10.1044/jshd.4701.02.

Stavropoulos, K. K. M., \& Carver, L. J. (2013). Research review: social motivation and oxytocin in autism-implications for joint attention development and intervention. Journal of Child Psychology and Psychiatry, 54(6), 603-618. doi:10.1111/jcpp.12061.

Stavropoulos, K. K., \& Carver, L. J. (2014a). Reward sensitivity to faces versus objects in children: an ERP study. Social Cognitive and Affective Neuroscience, 9(10), 1569-1575.

Stavropoulos, K. K. M., \& Carver, L. J. (2014b). Reward anticipation and processing of social versus nonsocial stimuli in children with and without autism spectrum disorders. Journal of Child Psychology and Psychiatry, 55(12), 1398-1408. doi:10.1111/jcpp.12270.

Stone, W. L., Ousley, O. Y., \& Littleford, C. D. (1997). Motor imitation in young children with autism: what's the object? Journal of Abnormal Child Psychology, 25(6), 475-485. doi:10.1023/A:1022685731726.

Tiegerman, D. E., \& Primavera, L. H. (1984). Imitating the autistic child: facilitating communicative gaze behavior. Journal of Autism and Developmental Disorders, 14(1), 27-38. doi:10.1007/BF02408553.

Tomasello, M., Carpenter, M., Call, J., Behne, T., \& Moll, H. (2005). Understanding and sharing intentions: the origins of cultural cognition. Behavioral and Brain Sciences, 28, 675-691.

Tronick, E., Als, H., Adamson, L., Wise, S., \& Brazelton, T. (1978). The infant's response to entrapment between contradictory messages in face-to-face interaction. Journal of American Academy of Child Psychiatry, 17, 1-13.
Uzgiris, I. C. (1981). Two functions of imitation during infancy. International Journal of Behavioral Development, 4(1), 1-12. doi: 10.1177/016502548100400101.

Vanvuchelen, M., Roeyers, H., \& Weerdt, W. D. (2007). Nature of motor imitation problems in school-aged boys with autism: a motor or a cognitive problem? Autism, 11(3), 225-240. doi:10.1177/ 1362361307076846.

Watson-Jones, R. E., Legare, C. H., Whitehouse, H., \& Clegg, J. M. (2014). Task-specific effects of ostracism on imitative fidelity in early childhood. Evolution and Human Behavior, 35(3), 204-210.

Whiten, A., \& Brown, J. (1998). Imitation and the reading of other minds: perspectives from the study of autism, normal children, and nonhuman primates. In S. Braten (Ed.), Intersubjective communication and emotion in early ontogeny (pp. 260-280). New York: Cambridge University Press.

Williams, J. H. G., Whiten, A., \& Singh, T. (2004). A systematic review of action imitation in autistic spectrum disorder. Journal of Autism and Developmental Disorders, 34(3), 285-299. doi:10.1023/ B:JADD.0000029551.56735.3a.

Zachor, D. A., Ilanit, T., \& Itzchak, E. B. (2010). Autism severity and motor abilities correlates of imitation situations in children with autism spectrum disorders. Research in Autism Spectrum Disorders, 4(3), 438-443. doi:10.1016/j.rasd.2009.10.016.

Zack, E., Barr, R., Gerhardstein, P., Dickerson, K., \& Meltzoff, A. N. (2009). Infant imitation from television using novel touch screen technology. British Journal of Developmental Psychology, 27(1), 13-26. doi:10.1348/026151008X334700. 